\title{
Cyclin B1 Peptide-pulsed Autologous Dendritic Cell Vaccine
}

National Cancer Institute

\section{Source}

National Cancer Institute. Cyclin B1 Peptide-pulsed Autologous Dendritic Cell Vaccine. NCI

Thesaurus. Code C97665.

A cell-based cancer vaccine comprised of autologous dendritic cells (DCs) pulsed with cyclin B1 peptide, with potential immunostimulatory and antineoplastic activities. Upon administration, cyclin B1 peptide-pulsed autologous dendritic cell vaccine may stimulate anti-tumoral cytotoxic T lymphocyte (CTL) and anti-cyclin B1 antibody responses against cyclin B1-expressing cancer cells, resulting in tumor cell lysis. Cyclin B1, a key regulator of the cell cycle and cell division, is overexpressed in a variety of cancer cells. 